\title{
Foramen Magnum Decompression and Duraplasty is Superior to Only Foramen Magnum Decompression in Chiari Malformation Type 1 Associated with Syringomyelia in Adults
}

\author{
Mehmet Sabri Gürbüz ${ }^{1}$, Mehmet Zafer Berkman ${ }^{2}$, Emre Ünal ${ }^{3}$, \\ Elif Akpınar ${ }^{4}$, Şevki Gök ${ }^{5}$, Metin Orakdöğen ${ }^{5}$, Salih Aydın ${ }^{1}$ \\ ${ }^{1}$ Neurosurgery Clinic, Emsey Hospital, Istanbul, Turkey \\ ${ }^{2}$ Neurosurgery Clinic, Acibadem Hospital, Istanbul, Turkey \\ ${ }^{3}$ Neurosurgery Clinic, Agri Public Hospital, Agri, Turkey \\ ${ }^{4}$ Neurosurgery Clinic, Sanliurfa Public Hospital, Sanliurfa, Turkey \\ ${ }^{5}$ Department of Neurosurgery, Haydarpasa Numune Training Hospital, Istanbul, Turkey
}

\section{Study Design: Retrospective cohort study.}

Purpose: To compare surgical results of foramen magnum decompression with and without duraplasty in Chiari malformation type 1 (CM-1) associated syringomyelia (SM).

Overview of Literature: The optimal surgical treatment of CM-1 associated with SM is unclear.

Methods: Twenty-five cases of CM-1 with SM were included. There were 12 patients (48\%) in the non-duraplasty group and 13 patients (52\%) in the duraplasty group. The rate of improvement, state of postoperative SM size, amount of tonsillar herniation, preoperative symptom duration, complications and reoperation rates were analysed.

Results: The rate of clinical improvement was significantly higher with duraplasty $(84.6 \%)$ than without $(33.3 \%, p<0.05)$. The rate of postoperative syrinx regression was significantly higher in the duraplasty group (84.6\%) than in the non-duraplasty group (33.3\%, $p<0.05)$. One case in the duraplasty group needed a reoperation compared with five cases in the non-duraplasty group $(p=0.059)$. Conclusions: Duraplasty is superior to non-duraplasty in CM-1 associated with SM despite a slightly higher complication rate.

Keywords: Chiari malformation type 1; Syringomyelia; Duraplasty; Non-duraplasty; Foramen magnum decompression

\section{Introduction}

Chiari malformation type $1(\mathrm{CM}-1)$ is defined as the downward displacement of the cerebellar tonsils and the medial portions of the inferior cerebellar lobules through the foraman magnum into the upper cervical spinal canal.
Obstruction of cerebral spinal fluid (CSF) at the level of the foramen magnum, and thus altered CSF dynamics, result in syringomyelia (SM), a longitudinal cystic cavity in the spinal cord $[1,2]$.

In $90 \%$ of the cases, $\mathrm{SM}$ is associated with $\mathrm{CM}-1$, in which the sucess rate of surgery varies from $45 \%$ to $87 \%$.

Received Jan 25, 2015; Revised Mar 2, 2015; Accepted Mar 2, 2015

Corresponding author: Mehmet Sabri Gürbüz

Neurosurgery Clinic, Emsey Hospital, Çamlık mah. Selçuklu cad. No:20 34912 Pendik, Istanbul, Turkey

Tel: +90-216-585-3700, Fax: +90-216-646-0096, E-mail: mehmetsabrigurbuz@gmail.com 
These patients present with either findings of SM or of brainstem compression $[3,4]$.

There is no consensus regarding the ideal surgical procedure for CM-1 associated with SM [2]. Despite the fact that many different treatment modalities have been studied and proposed, the optimal surgical treatment of CM-1 associated with SM is still unclear. Various surgical approaches include foramen magnum decompression (FMD) with and without duraplasty, syringopleural (SP) shunting, syringostomy, obex plugging, syringosubarachnoid shunting and fourth ventriculosubarachnoid shunting. Some authors advocate that only FMD is sufficient [5-7], whereas others approve of duraplasty or additional procedures including different types of shunting $[1,8,9]$. In the present study we compare the surgical results of FMD with and without duraplasty in CM-1 associated with SM in the light of current literature.

\section{Materials and Methods}

Twenty-five cases of SM associated CM-1 operated at our institute from 2005 to 2013 were retrospectively analysed. The cases were identified from the hospital medical archives. The epidemiological information, clinical presentation, radiological findings, regression rate of the syrinx, the type of surgery (duraplasty or non-duraplasty) and the clinical outcome were determined. There were no significant differences in age, gender and grade of symptoms between the groups.

In line with the literature [2], patients who were under 15 years old, patients with other types of CM, patients with other associated malformations such as basillar invagination or other craniovertebral anomalies, and patients who were treated by other methods such as SP shunting were excluded from the present study. Indications for surgery were progressive disabling symptoms as shown in Table 1, additional to a radiological diagnosis. Our criterion for selecting duraplasty in addition to FMD was the presence of a relatively aggressive, large-sized SM.

All patients underwent a decompressive suboccipital craniectomy extending at least $3 \mathrm{~cm}$ above the foramen magnum with a width of at least $4 \mathrm{~cm}$, and a $\mathrm{C} 1$ laminectomy was performed as described in the literature $[1,10$ $12]$. The non-duraplsty group (only FMD with no manipulation to the dura mater) consisted of 12 patients and the duraplasty group (FMD and duraplasty using a galeal autograft) consisted of 13 patients.
Table 1. Distribution of preoperative symptoms

\begin{tabular}{lc} 
Variable & No. (\%) \\
Hypoesthesia & $17(68)$ \\
Head and neck pain & $16(64)$ \\
\hline Hyperreflexia & $9(36)$ \\
Motor deficit & $9(36)$ \\
\hline Temperature discrimination & $7(28)$ \\
\hline Pathological reflex & $7(28)$ \\
\hline Extremity pain & $5(20)$ \\
\hline Cerebellar sign & $4(16)$ \\
\hline Imbalance & $3(12)$ \\
Cranial nerve sign & $3(12)$ \\
\hline Hearing disorder & $2(8)$ \\
\hline Gait disturbance & $2(8)$ \\
\hline Drop attack & $1(4)$ \\
\hline
\end{tabular}

Yilmaz et al. [13] reported a grading system for the amount of tonsiller herniation according to the position of the tonsils in relation to the posterior arcus of $\mathrm{C} 1$, and made a decision on the surgical method based on this grading system. Similar to this, we graded the amount of tonsillary herniation $(\mathrm{TH})$ using a more simple method according to the length of tonsiller descent from the foramen magnum in milimeters $(\mathrm{mm})$ as being less than 10 $\mathrm{mm}$ or more than $10 \mathrm{~mm}$. The preoperative symptom duration was divided into less than 36 months and more than 36 months. The preoperative and postoperative state of the SM cavity was measured using the ratio of the syrinx diameter to the diameter of the spinal canal, in line with the literature (Fig. 1). We evaluated the postoperative clinical conditions of the patients by examining the magnetic resonance imagings (MRIs) taken in the first, sixth and twelfth month following the operation. Similarly, patients' clinical examinations were carried out and compared with their preoperative examinations in the first, sixth and twelfth month following the operation (Fig. 2). The postoperative clinical conditions of the patients were assessed by clinical examination and face-to-face interview for the comparison of their current condition to the preoperative signs and symptoms. The postoperative states of the patients were classified as 'same and stabilized' meaning not worsened, 'improved' meaning better than the preoperative clinical condition and 'worsened', as suggested in the literature [12]. 


\section{Results}

The ages of the patients were 16-52, with a mean of 32 years old. The follow-up period was between 12-75

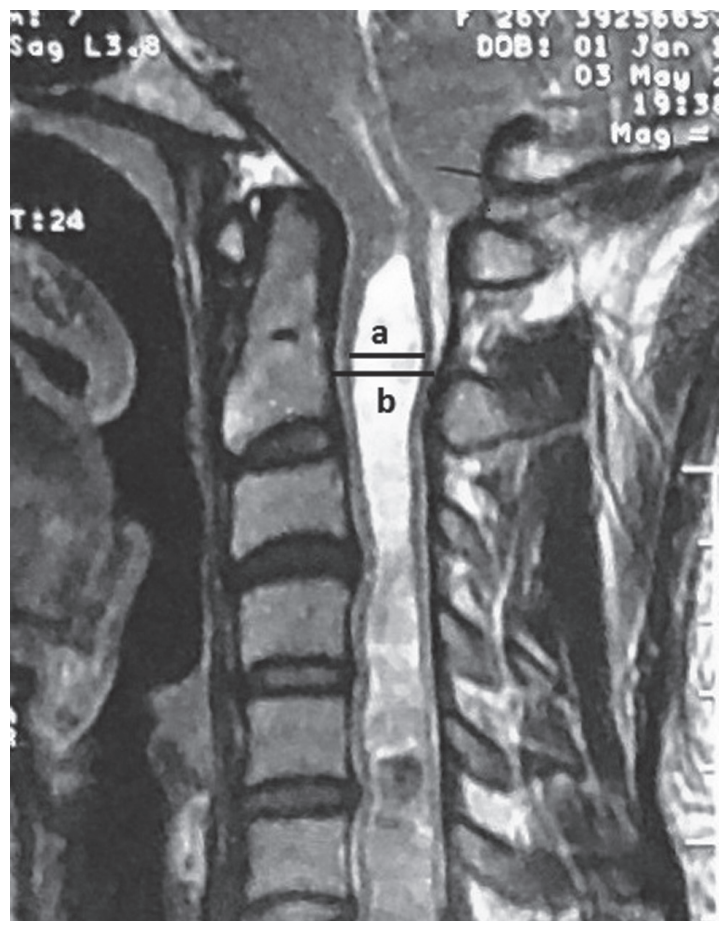

Fig. 1. The measurement of the ratio of the diameter of the syrinx (a) to the diameter of the vertebral canal (b) is seen on T2weighted sagittal cervical magnetic resonance imaging scan. months, with a mean of 44 months. Thirteen patients (52\%) were male and twelve (48\%) were female. The preoperative symptom duration was less than 36 months in 16 patients (64\%) and more than 36 months in 9 patients (36\%). The amount of $\mathrm{TH}$ was less than $10 \mathrm{~mm}$ in $15 \mathrm{pa}-$ tients $(60 \%)$ and more than $10 \mathrm{~mm}$ in 10 patients $(40 \%)$.

FMD alone was performed in 12 patients (nonduraplasty group) and FMD with duraplasty (duraplasty group) was performed in 13 patients. The rate of clinical improvement was significantly higher with duraplasty $(84.6 \%)$ than without $(33.3 \%, p<0.05)$ (Table 2). The rate of postoperative syrinx regression was significantly higher with duraplasty $(84.6 \%)$ than without $(33.3 \%, p<0.05)$. The syrinx size remained unchanged in $15.4 \%$ of patients who underwent duraplasty and $66.7 \%$ of patients who did not (Table 2). Ten patients had persistant SM, with two of these being in the duraplasty group, who subsequently improved clinically. However, none of the patients with persistent SM who were in the non-duraplasty group $(n=8)$ improved clinically, and were evaluated as the same clinical condition as seen preoperatively, nevertheless none of them worsened.

One case in the duraplasty group needed to be reoperated because the syrinx did not regress and the clinical symptoms did not improve, and an additional SP shunt operation was carried out. However, five cases in the nonduraplasty group were reoperated, and all of them underwent an additional duraplasty, four of which improved
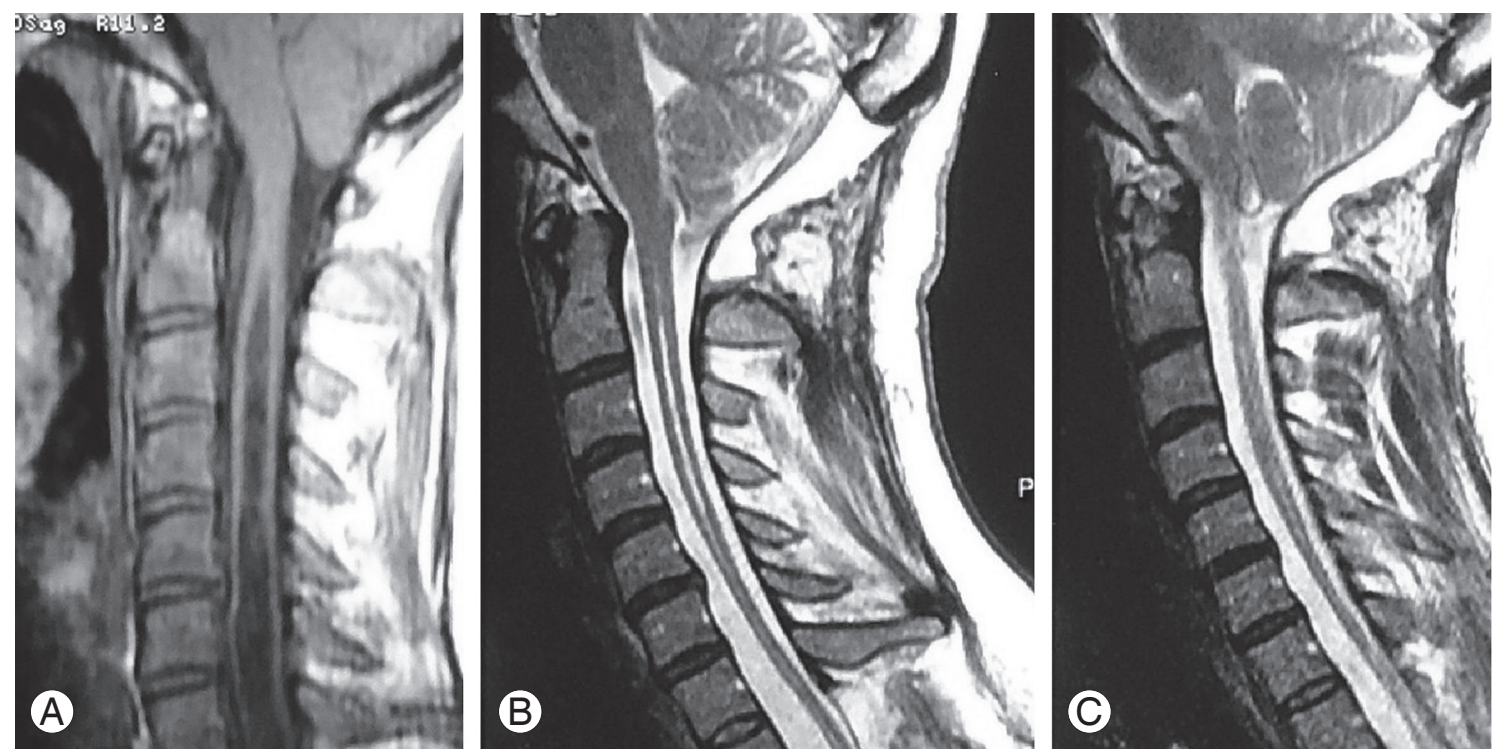

Fig. 2. Regression of the syrinx is seen in cervical sagittal magnetic resonance imaging scans taken in postoperative (A) first, (B) sixth, and (C) twelfth month of operation. 
Table 2. Comparison of clinical improvement, postoperative syrinx regression, reoperation rate and complication rates between duraplasty and nonduraplasty techniques

\begin{tabular}{|c|c|c|c|}
\hline \multirow{2}{*}{ Variable } & \multicolumn{2}{|c|}{ Technique } & \multirow{2}{*}{$p$-value ${ }^{\text {a) }}$} \\
\hline & Non-duraplasty & Duraplasty & \\
\hline Syrinx & & & $0.013^{b /}$ \\
\hline Same & $8(66.7)$ & $2(15.4)$ & \\
\hline Regressed & 4 (33.3) & 11 (84.6) & \\
\hline Clinical outcome & & & $0.013^{b)}$ \\
\hline Same & $8(66.7)$ & $2(15.4)$ & \\
\hline Improved & 4 (33.3) & $11(84.6)$ & \\
\hline Complication & $1(8.3)$ & 4 (30.8) & 0.186 \\
\hline Reoperation & $5(41.6)$ & $1(7.6)$ & 0.059 \\
\hline
\end{tabular}

Values are presented as number (\%).

${ }^{\text {al }}$ Fisher exact test; ${ }^{b /} p<0.05$.

during the follow-up period. One of these five patients whose syrinx aggravated despite additional duraplasty needed a SP shunt, after which the patient improved. Consequently, one case in the duraplasty group needed reoperation, whereas five cases in the non-duraplasty group needed reoperation, which is almost significant ( $p=0.059)$ (Table 2).

There was no statistically significant relationship between clinical improvement and preoperative symptom duration, neither was there any statistically significant relationship between clinical improvement and the amount of TH.

Postoperative infection was seen in one case in the nonduraplasty group, and two cases were seen in the duraplasty group. The overall complication rate was $20 \%$, with $8.3 \%$ in the non-duraplasty group and $30.8 \%$ in the duraplasty group, which is slightly higher but not statistically significant (Table 2).

\section{Discussion}

CM-1 includes a group of entities of congenital or acquired aetiology that have in common the descent of the cerebellar tonsils into the cervical spinal canal $[2,14]$. It is associated with SM in $30 \%-70 \%$ of cases $[5,15]$. Conversely, $90 \%$ of SM cases are associated with CM-1, in which the obstruction of CSF at the level of the foramen magnum alters CSF dynamics and results in SM $[4,16]$.

Clinical findings result from either brainstem compression at the level of foramen magnum or the cavity of SM $[2,4]$. Head and neck pain is the most commonly seen symptom in both children and adults $[4,12]$. Motor and sensory deficits, long tract findings, cerebellar findings, lower cranial nerve findings, nystagmus, hyperreflexia, and ataxia are other neurological findings that can be seen in CM-1 associated with SM $[2,5,17]$. The most commonly seen symptoms in our series were hypoesthesia, head and neck pain, hyperreflexia and motor deficits.

The diagnosis of CM-1 and SM is made by both clinical and radiological findings [11]. MRI is the gold standard in the diagnosis since it is non-invasive and has a good correlation with clinical findings $[2,18]$. Cine flow MRI studies have recently been introduced into clinical use and have gained importance in decision-making of the ideal surgical procedure $[14,16,19,20]$. Computed tomography (CT) is important since it reveals better contrast of the bones, gives information in axial, sagittal and coronal sections and makes three-dimensional reconstructions possible, especially for the understanding of the anatomy of the craniovertebral junction $[11,17,21]$. In the present study, the diagnoses of all cases were made based on a combination of clinical examination, CT and MRI.

Despite the fact that many different treatment modalities have been studied, the procedure of choice is established based on the clinical findings [22]. Some authors advocate that FMD alone is sufficient $[6,7,23]$, whereas others approve of duraplasty or additional procedures including different shunting procedures $[1,4,8,9]$. When signs of the spinal cord are prominent, and there is no sign of brainstem compression, SP shunting and followup is the optimal treatment choice, nevertheless in some 
cases additional SP shunting is needed during the followup period $[5,18,24]$. If the signs of the compression of both brain stem and spinal cord are prominent, the treatment of choice is FMD and SP shunting in the same session $[1,8,25]$. Our current study includes a comparison of two surgical techniques, FMD alone (non-duraplasty) and FMD with duraplasty. The rate of clinical improvement was significantly higher with duraplasty $(84.6 \%)$ than without $(33.3 \%, p<0.05)$. The rate of patients who remained unchanged was $15.4 \%$ with duraplasty and $66.7 \%$ without, revealing that clinical improvement relies on syrinx regression. These data also enable us to conclude that in CM-1 associated SM, FMD with duraplasty is superior to FMD alone, with respect to clinical improvement.

Erdogan et al. [1] reported that the symptoms and signs had been resolved in $83 \%$ of their patients following FMD without duraplasty, however the rate of syrinx regression was only $28 \%$. Improvement was seen in 20 of 23 patients in the series of Ramnarayan et al. [2], in which 8 of 11 patients benefited from posterior fossa decompression but the syrinx regressed only in $50 \%$ of the patients. Conversely, in the duraplasty group, 20 of 23 patients improved and the syrinx regressed in all of them. Romero and Pereira [9] reported that 4 of 6 patients improved without duraplasty and 9 of 10 patients improved with duraplasty, concluding that duraplasty is effective in CM-1 cases that are associated with SM. The previous study also reported that the syrinx regressed in all five patients with SM who underwent duraplasty, concluding that duraplasty is more effective in cases associated with SM [9]. In our present study, the rate of postoperative syrinx regression was significantly higher in the duraplasty group $(84.6 \%)$ than the non-duraplasty group (33.3\%, $p<0.05)$. The syrinx size remained unchanged in $15.4 \%$ of duraplasty patients and $66.7 \%$ of non-duraplasty patients. The clinical conditions of the patients having persistent SM remained unchanged (no improvement), however the clinical conditions of the patients whose SM regressed, achieved clinical improvement. Two of the ten patients with persistent SM were in the duraplasty group and they improved clinically. However, none of the patients with persistent SM who were in the non-duraplasty group $(n=8)$ improved clinically. These findings show that FMD and duraplasty is superior to FMD without duraplasty in CM-1 cases associated with SM.

Preoperative symptom duration is variably long in CM-1 associated with SM, since it is a slow progressive disease [26,27]. The mean preoperative symptom duration was 7.6 years in the series of Matsumoto and Symon [21], 6.2 years in the series of Arruda et al. [15] and 5.4 years in the series of Dyste et al. [3]. The preoperative symtom duration was $0-36$ months in $64 \%$ of our patients and $36-120$ months in $36 \%$ of our patients. In our series, no significant relationship was found between the surgical technique and the preoperative symptom duration.

Yilmaz et al. [13] classified cerebellar tonsillar descent (CTD) as grade I (the tonsil descended more than $5 \mathrm{~mm}$ below the foramen magnum but did not reach the $\mathrm{C} 1$ arch), grade II (the tonsil reached the $\mathrm{C} 1$ arch), and grade III (the tonsil descended over the $\mathrm{C} 1 \mathrm{arch}$ ). They reported that there were no statistically significant difference between preoperative and postoperative size of the SM cavity or the rate of improvement of duraplasty and nonduraplasty in CTD grade I and II, but in CTD grade III, a decrease in the syrinx cavity and clinical improvement were statistically better in the duraplasty group. In our present study, there was no statistically significant relationship between clinical improvement, syrinx regression and the amount of TH.

The complication rate is slightly higher with duraplasty than without [1]. Parker et al. [27] reported a $21.1 \%$ complication rate in their retrospective study including 114 patients in the duraplasty group. In their series, the most frequent complications were aseptic meningitis, symptomatic pseudomeningocele and CSF fistula. Klekamp [17] reported a $21.8 \%$ complication rate in their retrospective study including 359 patients in the duraplasty group. In the series of Hida et al. [28] postoperative meningitis was seen in two, and kyphosis in one, of the 33 patients in the non-duraplasty group. Arruda et al. [15] reported 23\% of pseudomeningocele and $6.6 \%$ of meningitis in their series including 60 patients in the duraplasty group. In our current study, the overall complication rate was $20 \%$, which is in line with the current literature. The postoperative complication rate is $8.3 \%$ without duraplasty and $30.8 \%$ with, which is consistent with the literature. One case in the duraplasty group needed reoperation, whereas five cases in the non-duraplasty group needed reoperation, indicating that the surgical results with duraplasty are better without, which is almost significant $(p=0.059)$.

\section{Conclusions}

FMD with duraplasty is superior to non-duraplasty (FMD 
only) in CM-1 associated with SM, despite a slightly higher complication rate. However, since the number of cases in our series is limited, this conclusion needs to be verified with a larger series.

\section{Conflict of Interest}

No potential conflict of interest relevant to this article was reported.

\section{Acknowledgments}

The authors are grateful to the radiologists in their hospital for their prompt preoperative and postoperative radiological examinations and image processing work.

\section{References}

1. Erdogan E, Cansever T, Secer HI, et al. The evaluation of surgical treatment options in the Chiari Malformation Type I. Turk Neurosurg 2010;20:303-13.

2. Ramnarayan R, Praharaj MS, Jayakumar PN. Chiari 1 malformations: an Indian hospital experience. Singapore Med J 2008;49:1029-34.

3. Dyste GN, Menezes AH, VanGilder JC. Symptomatic Chiari malformations: an analysis of presentation, management, and long-term outcome. J Neurosurg 1989;71:159-68.

4. Rehman L, Akbar H, Bokhari I, Babar AK, AS MH, Arain SH. Posterior fossa decompression with duraplasty in Chiari-1 malformations. J Coll Physicians Surg Pak 2015;25:254-8.

5. Goel A, Desai K. Surgery for syringomyelia: an analysis based on 163 surgical cases. Acta Neurochir (Wien) 2000;142:293-301.

6. Navarro R, Olavarria G, Seshadri R, Gonzales-Portillo G, McLone DG, Tomita T. Surgical results of posterior fossa decompression for patients with Chiari I malformation. Childs Nerv Syst 2004;20:349-56.

7. Padget DH. Development of so-called dysraphism: with embryologic evidence of clinical Arnold-Chiari and Dandy-Walker malformations. Johns Hopkins Med J 1972;130:127-65.

8. Munshi I, Frim D, Stine-Reyes R, Weir BK, Hekmatpanah J, Brown F. Effects of posterior fossa decompression with and without duraplasty on Chiari malformation-associated hydromyelia. Neurosurgery
2000;46:1384-9.

9. Romero FR, Pereira CA. Suboccipital craniectomy with or without duraplasty: what is the best choice in patients with Chiari type 1 malformation? Arq Neuropsiquiatr 2010;68:623-6.

10. da Silva JA, dos Santos AA Jr, Melo LR, de Araujo AF, Regueira GP. Posterior fossa decompression with tonsillectomy in 104 cases of basilar impression, Chiari malformation and/or syringomyelia. Arq Neuropsiquiatr 2011;69:817-23.

11. Taricco MA, Melo LR. Retrospective study of patients with Chiari: malformation submitted to surgical treatment. Arq Neuropsiquiatr 2008;66:184-8.

12. Zhou DB, Zhao JZ, Zhang D, Zhao YL. Suboccipital bony decompression combined with removal of the dural band as treatment for Chiari I malformation. Chin Med J (Engl) 2004;117:1274-7.

13. Yilmaz A, Kanat A, Musluman AM, et al. When is duraplasty required in the surgical treatment of Chiari malformation type I based on tonsillar descending grading scale? World Neurosurg 2011;75:307-13.

14. Cahan LD, Bentson JR. Considerations in the diagnosis and treatment of syringomyelia and the Chiari malformation. J Neurosurg 1982;57:24-31.

15. Arruda JA, Costa CM, Tella Jr OI. Results of the treatment of syringomyelia associated with Chiari malformation: analysis of 60 cases. Arq Neuropsiquiatr 2004;62:237-44.

16. McGirt MJ, Nimjee SM, Floyd J, Bulsara KR, George TM. Correlation of cerebrospinal fluid flow dynamics and headache in Chiari I malformation. Neurosurgery 2005;56:716-21.

17. Klekamp J. Surgical treatment of Chiari I malformation: analysis of intraoperative findings, complications, and outcome for 371 foramen magnum decompressions. Neurosurgery 2012;71:365-80.

18. Fujii K, Natori Y, Nakagaki H, Fukui M. Management of syringomyelia associated with Chiari malformation: comparative study of syrinx size and symptoms by magnetic resonance imaging. Surg Neurol 1991; 36:281-5.

19. Koc K, Anik Y, Anik I, Cabuk B, Ceylan S. Chiari 1 malformation with syringomyelia: correlation of phase-contrast cine MR imaging and outcome. Turk Neurosurg 2007;17:183-92.

20. Panigrahi M, Reddy BP, Reddy AK, Reddy JJ. CSF flow study in Chiari I malformation. Childs Nerv 
Syst 2004;20:336-40.

21. Matsumoto T, Symon L. Surgical management of syringomyelia: current results. Surg Neurol 1989;32: 258-65.

22. Bindal AK, Dunsker SB, Tew JM Jr. Chiari I malformation: classification and management. Neurosurgery 1995;37:1069-74.

23. Batzdorf U. Chiari I malformation with syringomyelia: evaluation of surgical therapy by magnetic resonance imaging. J Neurosurg 1988;68:726-30.

24. Ma J, You C, Chen H, Huang S, Ieong C. Cerebellar tonsillectomy with suboccipital decompression and duraplasty by small incision for Chiari I malformation (with syringomyelia): long term follow-up of 76 surgically treated cases. Turk Neurosurg 2012;22:274-9.
25. Garcia-Uria J, Leunda G, Carrillo R, Bravo G. Syringomyelia: long-term results after posterior fossa decompression. J Neurosurg 1981;54:380-3.

26. Dyste GN, Menezes AH. Presentation and management of pediatric Chiari malformations without myelodysplasia. Neurosurgery 1988;23:589-97.

27. Parker SR, Harris P, Cummings TJ, George T, Fuchs H, Grant G. Complications following decompression of Chiari malformation Type I in children: dural graft or sealant? J Neurosurg Pediatr 2011;8:177-83.

28. Hida K, Iwasaki Y, Koyanagi I, Sawamura Y, Abe H. Surgical indication and results of foramen magnum decompression versus syringosubarachnoid shunting for syringomyelia associated with Chiari I malformation. Neurosurgery 1995;37:673-8. 